\title{
Big Data "Kill Cooked" Management Policy Tool Selection
}

\author{
Yuxia Zhang \\ Quanzhou Normal University, \\ Fujian, China
}

\begin{abstract}
Since 2018, big data kill cooked has become the most important public topic in the Internet industry. The practice of big data kill cooked not only deviates from the most basic business ethics and violates the principle of good faith management, but also deprives consumers of the right to know and the right to choose. It seriously damages the legitimate rights and interests of consumers. The most important choice of policy tools for governance is that supervision should be in place, laws should be strengthened, and rigid laws and regulations should be used to severely punish it. Meanwhile, joint efforts should be made to strengthen social supervision, enterprise self-discipline and personal prevention.
\end{abstract}

Keywords-Big data; Kill cooked; Policy tools

\section{INTRODUCTION}

In March 2018, the word "big data killcooked" came to the fore. Some Internet companies were criticized for using big data to price different users on the same product. For a time, big data killcooked has become the most important public topic in the entire Internet industry. Is it illegal? On the basis of analyzing the chaos of killing ripeness in big data killcooked and its causes, this paper analyzes the legal rationality of killing ripeness in big data, and according to the policy tool theory put forward by Canadian scholars Michael Howlett and M.Ramesh, This paper puts forward some suggestions on the choice of policy tools to control big data kill cooked.

\section{FIRST, “KILL COOKED" IS LIKE A GHOST COMING WITH THE ADVENT OF BIG DATA ERA.}

The so-called "big data kill cooked ", is refers to the business with big data technology to collect user information about consumer behavior, from a variety of seemingly unrelated fragments behavior and scenario analysis "work out" the user's personalized consumer preferences, habits and level of accurate information and data model, and then precise classification positioning, "look at the food," differential pricing, the kill cooked without mercy, so as to realize accurate orientation of marketing and maximize returns. According to a survey by China youth daily, 51.3 percent of respondents said they had experienced Internet companies' use of big data to "kill cooked".

In fact, "big data kill cooked" is a common phenomenon in recent years. Similar situation exists in films, air tickets, travel, hotels, e-commerce and other platforms that fluctuate in price. In particular, online travel platforms are quite common. But

Foundation Project:

1. 2018 Fujian Province Young and Middle-aged Teacher Education Research Project "I Offer Good Strategies for Building New Fujian" (United Front Work Project) (Key Funding Project) (JZ180019).

2. Fujian Provincial Education Science "Thirteenth Five-Year Plan" 2017

Cross-Strait Vocational Education Special Research Project (FJJKHX17-077).

3.Quanzhou Normal University 2017 Open Experimental Project

(20170159)

4.Quanzhou Normal University Student Innovation and

Entrepreneurship Training Program Project Funding(201810399120)

*Corresponding author: Xiaofang Wang, weop3914985(2018,cthe Authors. Published by Atlantis Press. "big data knows new tricks" than conventional wisdom. First of all, big data is used for "user portrait" to construct consumption trap. Second, the use of information asymmetry, sitting prices, different user prices are different. One user posted on the Internet that he and his family paid different prices for different phones at the same time on the same flight. Take ctrip as an example. Except for the same booking time, different users have booked the same hotel room, but they have given different quotations. It's expensive not to buy. According to media reports, one netizen claimed to have booked a ticket on a travel platform and that the selected flight would go up every time he saw it. The same merchant, the same product, different consumer faces different price however, appear even the member price, old customer price is more expensive than normal price and the platform price is more expensive than the hotel front desk price absurd phenomenon [1].

Third, default bundling, malicious tying. Some electronic business platforms and online travel platforms have set many traps. The most common is the default bundling. Some netizens check out the VIP lounge, hotel coupons and other services. The next time the order is placed, the system will bind the corresponding services by default.

Fourth, make the overlord clause. Some online travel platforms take advantage of their strong position to force rules and introduce various overlord clauses, which either limit the choice of consumers or impose arbitrary fees and extra fees on consumers, which have been criticized by businesses and consumers. For example, the third-party ticketing platform stipulates that special price airfares are not allowed to be changed, extra fees are charged for cancellation and alteration, and there are even absurd phenomena that the refund fee of air tickets is more expensive than the original price of air tickets, which are frequently complained by consumers. The survey showed that $75.5 \%$ of respondents believed that they violated consumers' right to fair trade [2]. According to Article 3 of the National Development and Reform Commission's provisions on the Prohibition of Price Fraud, "Price Fraud refers to an operator who deceives by using a false or misleading pricing form or price method," The act of inducing a consumer or other operator to engage in a transaction with him ". According to this definition, "big data kill cooked" is a clear violation of the regulations, is a typical price fraud, and is contrary to the spirit of the law. 


\section{SECOND, THE BIG DATA ERA WHY THE EMERGENCE OF "KILL COOKED " CHAOS?}

The main reasons for the phenomenon of "killing cooked" in big data era are as follows:

\section{A. Lack of Relevant Laws and Weak Market Supervision}

The legal nature of big data is ambiguous. At present, China's laws related to big data are mainly the price law, the law on protection of consumer rights and interests and the law on anti-monopoly law. However, the formulation of these laws does not quite match the business based on big data analysis in the Internet era. For example, the threshold of price discrimination in the anti-monopoly law is very high. First, operators are required to have a dominant market position, and second, "there is no legitimate reason". The independent pricing of Internet enterprises can fully argue that the so-called "kill cooked" is a legitimate pricing strategy, and it is difficult to directly and effectively regulate the "kill cooked" behaviors of big data in accordance with existing laws [3]. The lack of market supervision in China is an important reason for the phenomenon of "killing cooked" big data. Because big data "kill cooked" behavior has very strong concealment sex, have different "kill cooked" behavior to different user, so individual user is difficult to detect directly. At present, there are still many problems in China's traditional offline inspection and post-disposal supervision and management, such as low discovery rate, difficulty in obtaining evidence and high inspection cost.

\section{B. Driven by the Interests of Merchants, the Industry Self- Discipline Mechanism Has Not Yet Been Established}

Big data era, pervasive information gathering made everyone is a hollow man, for specifics, affectionately, zhihu APP, all in varying degrees to collect user and relevant contact information, enterprise use of big data collecting information this kind of practice, is in order to obtain a bigger benefit, but its proper channels of access to information, without the knowledge of the user, the user is willing to be seen. Even if the fundamental purpose of the enterprise is to obtain profits, it should be" Gentlemen love fortune, in a proper way ".

One of the main reasons for the phenomenon of big data "ripeness" is the lack of self-supervision in the industry, which makes various industries feel profitable to imitate each other instead of supervising each other. The lack of industry selfdiscipline mechanism makes some enterprises more unafraid to use big data to "kill cooked".

\section{Lack of Social Supervision Services and Low Price Sensitivity of Consumers}

The lack of social supervision and service, make some enterprise on the use of big data to seek improper interests more harsh, manifested in two aspects: on the one hand, because for big data analysis and utilization of the lack of monitoring tools, makes big data "kill cooked" behavior, it is hard to find a few businessmen, enterprises will be more technical superiority, encourages the use of big data "kill cooked " ways to rule; On the other hand, consumers are less aware of the types of bad businesses that use big data to harm their interests, and consumers are less alert to big data. Therefore, there is a lack of social supervision service for big data at present. Consumers' sensitivity to price is also one of the factors that make them familiar. Some people are more sensitive to price. They like to shop around, while others don't care too much. Many businesses always set a pattern in advance to help them obtain greater benefits. Due to serious information asymmetry, consumers are in a weak position.

\section{BIG DATA KILL COOKED PHENOMENON MANAGEMENT POLICY TOOL ANALYSIS}

"Big data kill cooked" behavior, not only deviated from the basic business ethics and corporate value, violating the principle of good faith management, and deprived of the right to know of consumers, options, serious harm the legitimate rights and interests of consumers, to "kill cooked" big data, consumer traps, overlord terms, malicious for sale, such as chaos, must undertake administrative. Policy tools for governance can be combined with mandatory, hybrid and voluntary tools. The most important thing is that the supervision should be put in place, and laws should be used to firmly punish all kinds of chaos in the e-commerce industry, with rigid laws and regulations, so that the e-commerce platform can be properly punished, pay due costs, and effectively increase the illegal and illegal cost of harming consumers.

\section{A. Lmprove Laws and Regulations and Strengthen Market Supervision}

On big data kill familiar phenomenon in China so far have no clear legal provisions, for large data "kill" whether infringement of consumer rights and interests of the behavior, also need to be explicitly, at the legal level to further define the about "consumer privacy" and "differential pricing" legal boundary behavior, strengthens to individual consumer information in the form of legislation, the protection of the rights and interests. Only under the protection of law can the network environment be fresher, and big data develop better and develop more purely.

We will strengthen the linkage between supervision and innovation and enhance our capacity for regulatory innovation. An enterprise credit mechanism can be established to reflect the credit level of the enterprise and to publicize the enterprise's breach of trust. This mechanism mainly USES big data to obtain sales information of enterprises, which reflects the innovation of supervision. China has a large number of relevant regulatory departments, resulting in unclear rights and responsibilities. In order to better perform their duties and improve the effectiveness of supervision, it is necessary to strengthen the linkage of supervision. All departments should cooperate with each other to strengthen credit supervision, conduct in-depth investigation, and distinguish responsibilities.

\section{B. Establish a Self-discipline Mechanism for the Industry and Conduct Business in Good Faith}

The mutual supervision and self-discipline between industries will be better than the government's supervision. The establishment of the industry self-discipline mechanism can be 
started from the following aspects: establishing an industry self-discipline organization for the development and utilization of big data, jointly formulating the industry self-discipline convention, advocating that enterprises provide high-quality and personalized service concepts for the society with big data, and avoiding the value concept of" kill cooked". Encourage and guide enterprises to develop consumer notification agreements on big data analysis applications, including the scope of data collection, methods of analysis, goals to be achieved and the impact on users, so that consumers are happy to receive services; We will encourage enterprises to accept extensive social supervision, regularly issue reports on the development and utilization of big data, respect consumers' right to know and fair trading, and ensure consumers' personal information security.

\section{Improve the Level of Social Supervision and Strengthen Personal Prevention by Consumers}

We will set up a special regulatory and rights protection agency to actively intervene in ACTS of " kill cooked", encourage consumers to report and complain about "killing ripe" businesses, and promptly investigate, punish and disclose information. An online exposure platform is set up to expose bad businesses that use big data to infringe consumers' rights and interests and increase their social risk costs. We will increase publicity efforts, publicize them through various forms and channels, and publicize them through .We Chat public account and online popular science articles of official media, so as to raise citizens' awareness level and awareness of prevention. We will improve the level of social supervision and technology, train relevant professionals and improve the level of social services. For consumers to strengthen personal prevention, increase price sensitivity, remember to blind impulse, once found, timely complaints, resolutely eliminate all kinds of killing familiar wind.

In short, big data is a double-edged word. Internet companies should make better use of big data to develop themselves, rather than to "kill ", to operate in good faith rather than opportunistic. Look forward to a better society.

\section{REFERENCE}

[1] Y.C. Du, R.B. Zhang, and Y.Y. Qu, "51.3 percent of interviewees have experienced the "death experience" of big data," China youth daily, edition 009, March 27, 2018

[2] Y.C. Du, R.B. Zhang, and Y.Y. Qu, "51.3 percent of interviewees have experienced the "death experience" of big data," China youth daily, March 27. 2018, edition 009

[3] R. Hu, "Big data kill cooked is essentially illega," Shenzhen Business Daily, A07 Edition, March 28. 2018. 